\title{
The opioid overdose epidemic: opportunities for pharmacists
}

\author{
This article was published in the following Dove Press journal: \\ Substance Abuse and Rehabilitation \\ 31 July 2017 \\ Number of times this article has been viewed
}

The USA is experiencing an opioid overdose epidemic. It has been driven largely by prescription opioids and intensified by a surge of illicit opioids (e.g., heroin and fentanyl). ${ }^{1,2}$ Drug-involved overdose, mainly opioids (e.g., prescription opioids and heroin), is a leading cause of accidental death in the USA. The opioid overdose epidemic has been escalating consistently for over a decade. ${ }^{2}$ Every day, an estimated 91 Americans die from opioid-related overdose. ${ }^{3}$ Opioid overdose appears to have disproportionally affected men, adults aged 25-64 years, and non-Hispanic whites. $^{2}$

The opioid overdose epidemic is related partly to an increase in the availability of both licit and illicit opioids as well as the current "suboptimal" system for pain management and related prescribing. ${ }^{2,4}$ The latter may be related to a lack of sufficient knowledge of behavioral and biological issues to treat chronic noncancer pain, overreliance on potentially high-risk treatments for pain such as prescribing opioids, inadequate tailoring of pain therapies to individuals, or insufficient reimbursement of non-opioid pain management strategies. ${ }^{4}$ Of note, pain is among the most common reasons for health care visits. Various data sources suggest that approximately $11 \%-40 \%$ of the US population report symptoms of chronic pain, with millions suffering from disabling pain. ${ }^{4}$ In an attempt to improve treatment for pain, there had been a pattern of broader prescribing of opioids for pain conditions over the past 2 decades. Availability of US Food and Drug Administration (FDA)-approved opioid medications, pharmaceutical companies' marketing campaigns, and inadequate education or knowledge about risks of prescribing opioids for managing chronic noncancer pain may have contributed to increases in prescribed opioids, opioid sales, and opioid prescriptions dispensed. ${ }^{4-6}$

Overall, primary sources of nonmedical opioid use or misuse are friends or family members, followed by physician's prescriptions or drug dealers. ${ }^{7}$ Approximately $20 \%$ of the patients who are prescribed opioids have received high quantities by either one or more physicians, and these are the type of patients likely at elevated risk for opioidrelated overdoses. ${ }^{8}$ Opioid sharing and diversion contribute to misuse and overdose. Research data also suggest that approximately $25 \%-66 \%$ of individuals who die of prescription drug overdoses use opioids which were prescribed to someone else. ${ }^{8}$ Therefore, pharmacists who dispense prescription medications and may have a regular contact with patients at risk for prescription opioid sharing, diversion, misuse, or overdose can play a vital role in prevention efforts and in the application of medication therapy management to improve patient care and avert medication-related problems. ${ }^{9,10}$
Correspondence: Li-Tzy Wu

Department of Psychiatry and

Behavioral Sciences, BOX 3903, Duke

University School of Medicine, Durham, NC 277I0, USA

Email litzy.wu@duke.edu
Substance Abuse and Rehabilitation 2017:8 53-55 
Earlier projects have demonstrated that pharmacist patient care services as part of health care teams were associated with improved clinical outcomes and lower health care costs in the management of chronic medical conditions. ${ }^{11}$

Pharmacists are often the last line of defense in monitoring for prescription drug misuse. Community pharmacies are ubiquitous. Over $90 \%$ of Americans live within 5 miles of a community pharmacy, thus providing residents with steady access to pharmacists' services. ${ }^{12}$ Adults with chronic pain or other chronic illnesses, opioid-using doctor shoppers, and individuals who may obtain opioids for sharing or diversion are likely to be visitors of community pharmacies. Hence, pharmacists are ideally positioned to engage in health care efforts and programs aimed at preventing or reducing prescription opioid misuse and overdose while also working to ensure access to medications for patients with legitimate chronic pain needs. A pharmacist has a corresponding responsibility with a prescriber to assure that prescriptions for controlled substances are issued for a legitimate medical purpose. As "gatekeepers," pharmacists assess controlled substance prescriptions and use prescription drug monitoring programs (PDMPs) or other tools to help identify red flags (e.g., diversion and improper prescribing). Pharmacists also actively educate patients about the proper use of medications, side effects, medication storage, and disposal; provide counseling for opioid-related health risk; and offer coordinated care and management of chronic illness. ${ }^{10,13}$

To date, community pharmacists are arguably underutilized and understudied health care professionals in the prevention of prescription drug misuse and overdose, and they can offer significant help in the management and treatment of opioid use disorder. While pharmacists across the nation have engaged in community- or pharmacy-based naloxone distribution programs to help reduce opioid-involved overdose mortality, research is still needed to understand the barriers to expanding naloxone distribution into rural or underserved areas and to evaluate both clinical and substance use treatment outcomes of those who received naloxone for opioid overdose reversal. ${ }^{10,14}$

In addition, there is limited research on opioid misuse prevention or interventions for opioid use disorder administered by pharmacists to patients in the pharmacy setting. Pharmacists are well aware of the existence of prescription drug problems in their patient populations and the community. Research data suggest that pharmacists are interested in engaging in activities to reduce opioid misuse/overdose and helping patients with opioid use problems through the provision of medication therapy education, addiction treatment information, counseling, or brief intervention. ${ }^{15-17}$ However, substantial barriers exist regarding the lack of substance misuse-related training or resources (e.g., information, staffing or infrastructure support, and financial incentive) to effectively engage pharmacists in prevention efforts and care coordination for treatment. There is a need to develop and test strategies and resources for enhancing pharmacists' willingness, skills, and confidence in communicating with patients regarding opioid misuse, collaborating with physicians to improve pain management and prevent opioid misuse, conducting screening for substance misuse, and referring patients to substance use treatment.

Further, the PDMP is a vital tool for pharmacists to help identify patients at risk for opioid prescription drug misuse or overdose, but it is vastly underutilized. A 2013 report estimated that only approximately $36 \%$ of licensed pharmacists register to use the PDMP. ${ }^{18}$ Although this number is increasing due to state laws enacted to increase PDMP enrollment and reporting, more research is needed to better understand barriers and facilitators for more effective utilization of PDMPs. Some research data also reveal the need for rigorous studies to better understand the impact of using the PDMP on the change of pharmacy practices (e.g., communicating with patients or prescribers when red flags are identified and dispensing opioid prescriptions). ${ }^{19}$

Finally, having real-time access to patients' electronic health records (EHRs) along with the PDMP would provide the community pharmacist with important information to assist in clinical decision-making and may help identify patients at risk for opioid use problems or overdose, thereby improving the provision of patient-centered services. Future research should investigate the linkage of EHRs with the PDMP and identify means to successfully integrate the PDMP and other decision support tools into pharmacy practices. ${ }^{20}$ Access to safe, highquality, and effective care for people suffering from chronic pain is a high priority that requires team-based, person-centered care strategies to minimize inappropriate opioid prescribing and dispensing as well as opioid sharing and diversion. Pharmacists can play a vital role in these efforts.

\section{Disclosure}

Li-Tzy Wu (UG1DA040317, R01MD007658) and Paolo Mannelli (UG1DA040317) have received research support from the National Institutes of Health. Li-Tzy Wu has received research support from Alkermes Inc. Paolo Mannelli has received research support from Orexo and Alkermes Inc and served on Scientific Advisory Boards for Alkermes Inc. Udi E Ghitza is an employee of the Center for the Clinical 
Trials Network of the National Institute on Drug Abuse, the National Institutes of Health. Dr Udi E Ghitza's participation in this publication arises from his role as a project scientist on a cooperative agreement (UG1DA040317), but he has not had and will not have any programmatic involvement with the noncooperative agreement grant cited (i.e., R01MD007658). Anne L Burns is Vice President of the Professional Affairs at the American Pharmacists Association. The opinions expressed in this paper are those of the authors, and they do not represent the official position of the US government, American Pharmacists Association, or the publisher of this journal. The authors report no other conflicts of interest in this work.

\section{References}

1. Hedegaard H, Chen LH, Warner M. Drug-poisoning deaths involving heroin: United States, 2000-2013. NCHS Data Brief. 2015;190:1-8.

2. Rudd RA, Seth P, David F, Scholl L. Increases in drug and opioidinvolved overdose deaths - United States, 2010-2015. MMWR Morb Mortal Wkly Rep. 2016;65(5051):1445-1452.

3. Centers for Disease Control and Prevention (CDC). Understanding the Epidemic; 2017. Available from: https://www.cdc.gov/drugoverdose/ epidemic/index.html. Accessed June 20, 2017.

4. National Institute of Health (NIH). National Pain Strategy: A Comprehensive Population Health-Level Strategy for Pain; 2017. Available from: https://iprcc.nih.gov/docs/HHSNational_Pain_Strategy.pdf. Accessed June 15, 2017.

5. Van Zee A. The promotion and marketing of oxycontin: commercial triumph, public health tragedy. Am J Public Health. 2009;99(2):221-227.

6. Volkow ND, Frieden TR, Hyde PS, Cha SS. Medication-assisted therapies - tackling the opioid-overdose epidemic. $N$ Engl $J$ Med. 2014;370(22):2063-2066.

7. Jones CM, Paulozzi LJ, Mack KA. Sources of prescription opioid pain relievers by frequency of past-year nonmedical use: United States, 2008-2011. JAMA Intern Med. 2014;174(5):802-803.

8. Centers for Disease Control and Prevention (CDC). CDC grand rounds: prescription drug overdoses - a U.S. epidemic. MMWR Morb Mortal Wkly Rep. 2012;61:10-13.
9. Brummel A, Lustig A, Westrich K, et al. Best practices: improving patient outcomes and costs in an ACO through comprehensive medication therapy management. J Manag Care Pharm. 2014;20(12):1152-1158.

10. Green TC, Dauria EF, Bratberg J, Davis CS, Walley AY. Orienting patients to greater opioid safety: models of community pharmacy-based naloxone. Harm Reduct J. 2015;12:25.

11. Centers for Disease Control and Prevention (CDC). Collaborative Practice Agreements and Pharmacists' Patient Care Services. A Resource for Decision Makers. Atlanta, GA: Centers for Disease Control and Prevention (CDC); 2013.

12. National Association of Chain Drug Stores (NACDS). Pharmacy: The Face of Neighborhood Health Care in America. RX IMPACT. 2017. Arlington, VA: NACDS; 2017.

13. American Society of Health-System Pharmacists (ASHP). ASHP statement on the pharmacist's role in substance abuse prevention, education, and assistance. Am J Health Syst Pharm. 2014;71(3):243-246.

14. Bachyrycz A, Shrestha S, Bleske BE, Tinker D, Bakhireva LN. Opioid overdose prevention through pharmacy-based naloxone prescription program: innovations in health care delivery. Subst Abus. 2017;38(1): $55-60$.

15. Cochran G, Field C, Lawson K, et al. Pharmacists' knowledge, attitudes and beliefs regarding screening and brief intervention for prescription opioid abuse: a survey of Utah and Texas pharmacists. J Pharm Health Serv Res. 2013;4(2):71-79.

16. Hagemeier NE, Murawski MM, Lopez NC, Alamian A, Pack RP. Theoretical exploration of Tennessee community pharmacists' perceptions regarding opioid pain reliever abuse communication. Res Social Adm Pharm. 2014;10(3):562-575.

17. Hagemeier NE, Alamian A, Murawski MM, Pack RP. Factors associated with provision of addiction treatment information by community pharmacists. J Subst Abuse Treat. 2015;52:67-72.

18. Bureau of Justice Assistance. Prescription Drug Monitoring Program (PDMP) Program Performance Report; 2016. Available from: https:// www.bja.gov/Publications/PDMP_PPR_Jan-Dec13.pdf. Accessed June 13, 2017.

19. Green TC, Mann MR, Bowman SE, et al. How does use of a prescription monitoring program change pharmacy practice? JAm Pharm Assoc (2003). 2013;53(3):273-281.

20. Norwood CW, Wright ER. Integration of prescription drug monitoring programs (PDMP) in pharmacy practice: improving clinical decisionmaking and supporting a pharmacist's professional judgment. Res Social Adm Pharm. 2016;12(2):257-266.

Dove Medical Press encourages responsible, free and frank academic debate. The content of the International Medical Case Reports Journal 'Editorial' section does not necessarily represent the views of Dove Medical Press, its officers, agents, employees, related entities or the International Medical Case Reports Journal editors. While all reasonable steps have been taken to confirm the content of each Editorial, Dove Medical Press accepts no liability in respect of the content of any Editorial, nor is it responsible for the content and accuracy of any Editorial.

Substance Abuse and Rehabilitation

\section{Publish your work in this journal}

Substance Abuse and Rehabilitation is an international, peer-reviewed, open access journal publishing original research, case reports, editorials, reviews and commentaries on all areas of addiction and substance abuse and options for treatment and rehabilitation. The manuscript management system is completely online and includes a very quick and fair peer-review system. Visit http://www.dovepress.com/testimonials.php to read real quotes from published authors. 